\title{
HINGLEY, Richard. O Imperialismo romano: novas perspectivas a partir da Bretanha. Trad. Luciano César Garcia Pinto. Organização de Renata Senna Garraffoni, Pedro Paulo A. Funari e Renato Pinto. São Paulo: Annablume, 2010.
}

Os estudos acerca do mundo clássico vêm recebendo, a partir do ponto de vista da História e da Arqueologia, propostas de análises inovadoras. Ao contrário das tradições interpretativas que concebiam as sociedades antigas como modelos de homogeneidade social e cultural, utilizando conceitos tais como legado, herança, civilização, helenização, romanização, alguns historiadores e arqueólogos que tematizam o mundo antigo têm direcionado seus esforços para o estudo das apropriações modernas da Antiguidade.

Inseridos em uma discussão epistemológica mais recente, esses estudos chamam a atenção para o aspecto discursivo dos estudos clássicos, rechaçando posturas objetivistas. Convergem, nesse sentido, para "uma reação subjetivista, que coloca no centro de qualquer visão sobre o passado o autor dessa visão, que vê de determinada posição social, econômica, histórica, de gênero (homem, mulher)" (Garraffoni; Funari, 2007: 4). Comumente vistos como afastados do campo da política moderna, os estudos sobre a Antiguidade, como é ressaltado por Martin Bernal, "têm sido marcados por uma atitude francamente política" (2005: 13).

É nessa perspectiva que está inserido o livro O Imperialismo Romano: novas perspectivas a partir da Bretanha de Richard Hingley, professor do Departamento de Arqueologia da Universidade de Durham, na Inglaterra. Este volume reúne quatro artigos, inéditos em língua portuguesa, publicados em primeira versão entre 1991 e 2008. Em comum entre eles é a pretensão de se analisar os modelos interpretativos utilizados nos estudos sobre a Roma clássica pelos estudiosos britânicos, no ensejo de desconstruir os discursos imperialistas do início do século $X X$ que fundamentaram leituras sobre 0 passado romano, tanto na História como na Arqueologia. A partir dessas críticas é que são propostas análises inovadoras, influenciadas, em grande medida, pelas teorias pós-colonialistas, que tentam construir interpretações mais flexíveis acerca do Império romano.

No capítulo de abertura, O "legado" de Roma: ascensão, declínio e queda da teoria da romanização (texto originalmente publicado em 1996), Hingley discute as mudanças sociais ocorridas com a chegada dos romanos na Bretanha, e como isso pode ter refletido na cultura material. Estabelece, então, uma discussão disposta em três tópicos com temáticas inter-relacionadas. 
No primeiro, seu intento é "examinar alguns dos modos pelos quais os britânicos usaram a imagem da Roma clássica para identificar e fundamentar suas próprias nacionalidade e expansão" (p.28). Muitos paralelos e associações com Roma foram estabelecidos durante os períodos medieval e moderno, principalmente entre os sistemas imperiais britânico e romano (p.29). Já no início do século XX, entre 1899 e 1914, um paralelo particular foi promovido por políticos e intelectuais que "argumentavam que a história de Roma fornecia 'moralidade' aos britânicos numa época de particular pressão internacional" (p.30). Esse paralelo romano, segundo Hingley, "foi empregado para definir uma linha de continuidade no desenvolvimento cultural europeu desde o passado clássico até o presente" (p.31).

O principal acadêmico do período estudado é o arqueólogo e historiador Francis Haverfield (1860-1919), pioneiro na Arqueologia sobre o período romano-britânico, que está "entre os estudiosos que advogavam pelo especial valor moral que os estudos sobre Roma tinham para os britânicos" (p.32). Um dos conceitos promovidos por Haverfield é o de "Romanização", do qual Hingley é crítico, onde é estabelecido "um modelo para o processo de mudança progressiva que tem muito em comum com os conceitos de 'progresso' e de 'desenvolvimento', próprios do século XIX e do início do século XX" (p.33). Essa idéia seria "comprovada" pela "transformação gradual da cultura material, na província, de nativa a romana, durante todos os três séculos e meio de dominação romana" (p.34).

No segundo tópico, Hingley percebe uma mudança ocorrida nos estudos sobre a "Romanização" nos últimos setenta anos, realizados por acadêmicos já no período de declínio ou posterior ao fim do Império Britânico: "a romanização deixou de ser vista como uma forma de progresso moral e social, mas sim vista à luz do desenvolvimento, ou aculturação, pelo qual a sociedade nativa, de imediato, adotou a cultura 'romana"' (p.34). Nesse momento, portanto, a teoria passaria por uma mudança conceitual, constituindo-se um processo de adoção cultural, não imposição. O trabalho de Martin Millet (1955-), professor de Arqueologia clássica da Universidade de Cambridge (Inglaterra), é, para Hingley, ilustrativo a esse respeito, onde "indivíduos bem-intencionados das elites imperial, tribal e local gentilmente demonstravam as vantagens dos novos costumes aos interessados da sua parentela, de seus clientes e de seus escravos, e permitiam - até mesmo encorajavam - mudanças voluntárias em seus modos de vida. (...) Considerou-se, então, que mudanças na cultura material eram direcionais e que tinham resultado de um desejo, da parte dos provinciais, de se tornarem romanos" (p.36).

Por fim, Hingley propõe discutir a contribuição das teorias pós-coloniais para uma crítica dos discursos anteriores, pois "trabalhos cuja análise é póscolonial podem permitir-nos, todavia, ver e considerar as perspectivas que motivaram os estudos passados e, também, sugerir esquemas amplos para novas formas de compreensão" (p.35). Questiona os modelos interpretativos que "ignoram o papel ativo da sociedade nativa em determinar a função, o valor e o papel de suas próprias posses" (p.37), bem como as abordagens que sugerem que há um fenômeno tal como uma cultura material "romana": "vários itens materiais que são tomados como índice de 'romanização' não provieram de Roma, mas de outras áreas do Império" (p.37).

Sendo assim, o que Hingley espera de uma Arqueologia acerca da Bretanha Romana é que ela "aceite a teoria de que indivíduos e comunidades 
adotavam ativamente novos símbolos e ideias para criar ou manter o controle das relações de poder; mas, ao mesmo tempo, ela pode opor-se a isso com uma segunda teoria: comunidades e indivíduos dominados reagiam às tentativas de dominá-los por meio de atos de oposição que tinham correlatos materiais" (p.41).

No segundo capítulo, O campo da Bretanha Romana: o significado das formas de assentamento rural (texto originalmente publicado em 1991), Hingley direciona sua atenção aos estudos dos assentamentos rurais romanobritânicos. Aponta que seu objetivo será "considerar certos conceitos e temas relevantes ao estudo do assentamento rural Romano-britânico. (...) a intenção é considerar um conjunto de modelos que examinam a natureza das evidências" (p.49). Considera que os "sítios de assentamento romano-britânico variam em tamanho, forma, abundância, função e localização" (p.50), e esses aspectos tornam-se importantes para um estudo da organização sócio-econômica das comunidades das províncias da Bretanha Romana. Também é possível, por meio da cultura material, vislumbrar o propósito econômico de cada assentamento, seja ele comércio, indústria ou agricultura.

É tratado cada tipo de assentamento individualmente, oferecendo suas definições e principais características materiais: Outros assentamentos rurais (p.52); Pequenas cidades (p.52) - antes de explorar em detalhe a organização dos assentamentos e da paisagem que os cercam - A organização do assentamento (p.53); A organização da paisagem (p.58).

É a partir de um estudo crítico dos conceitos e temas que vêm sendo empregados para a interpretação da cultura material dos assentamentos romano-britânicos, bem como os modelos interpretativos arqueológicos utilizados, que Hingley procura mostrar que, dependendo do modelo utilizado, uma determinada situação sócio-econômica pode parecer muito mais complexa quando comparada a visões mais tradicionais.

No capítulo seguinte, Diversidade e unidade culturais: Império e Roma (texto inédito), Hingley escolhe como temática a ser desenvolvida a diversidade cultural do mundo da Roma clássica, e aponta como objetivo "explorar um aspecto da relação entre o mundo da Roma antiga e os nossos tempos atuais, ao destacar uma perspectiva que se desenvolve no interior dos estudos clássicos: a análise da diversidade, pluralidade e heterogeneidade culturais" (p.67). A proposta é analisar a questão do contexto político-social no interior do qual tais ideias emergiram e estão florescendo. Destaca, também, a questão da contemporaneidade dos estudos sobre a Roma clássica que "com freqüência explicam os fenômenos históricos antigos nos termos que satisfazem os gostos e os interesses modernos" (p.68), e o uso de Roma ao longo da história, pois "desde a queda do Império romano no ocidente, durante o século $V$ d.C., a Roma clássica continuou a ser usada para ilustrar o presente de formas variadas e contrastantes" (p.69). Ilustrativo a esse respeito é o conceito de "Romanização", uma categoria analítica criada, em especial entre os séculos XIX e XX, para enfatizar "um processo de 'progresso' desde uma cultura 'bárbara' até uma 'romana' na expansão do Império" (p.71), criando, dessa forma, polaridades e hierarquias que acabaram se configurando como ferramentas conceituais para o uso das nações imperialistas modernas. Nesse sentido, a atenção deve ser voltada, segundo Hingley, "para o papel ideológico desempenhado pela arqueologia clássica e pela história antiga ao longo de toda a era moderna" (p.73). 
Como crítica a essa visão, Hingley apresenta estudos que apontam para um cenário cultural e identitário muito complexo e diversificado, onde "a cultura 'romana' não é mais vista como uma entidade monolítica e claramente delimitada, mas como derivada de uma variedade de fontes ao longo do Mediterrâneo" (p.75), bem como estudos do início do século XXI que "começaram a fragmentar a identidade romana, ao se voltarem para interpretações mais complexas que, com freqüência, valem-se de vestígios materiais" (p.77). Menciona alguns estudiosos que vêm adotando essa perspectiva ao tratar da Roma clássica como Nicola Terrenato, Greg Woolf, Carol van Driel-Murray e Emma Dench.

Outras questões ainda são tratadas por Hingley como o conhecimento do latim, a urbanização, a militarização e a marginalização no Império romano para apresentar um cenário de grande heterogeneidade no mundo romano. Por fim, aponta para a urgência do questionamento acerca dos propósitos, teorias e métodos relativos aos estudos contemporâneos sobre Roma. Ressalta que "os estudiosos do mundo clássico deveriam trabalhar a fim de procurar o contexto em que nosso entendimento do imperialismo romano se desenvolveu" (p.92). E conclui com um alerta: "se não encararmos o contexto político do trabalho que produzimos, seguiremos uma longa tradição acadêmica de recriar o fantasioso e o impossível: um campo neutro e apolítico dentro do qual os estudos clássicos pudessem funcionar" (p.93).

No último capítulo, O Muro de Adriano em teoria: uma nova agenda (texto originalmente publicado em 2008), Hingley inicia a discussão considerando a ocorrência de um enigma, qual seja, "o declínio sério e dramático, nas universidades britânicas, da pesquisa relativa ao primeiro monumento romano na Bretanha" (p.105). O monumento em questão é o Muro de Adriano, assim conhecido por ter sido construído por volta de 120 d.C., a mando de Públio Élio Trajano Adriano, imperador romano entre 117 e 138. Acrescenta, ainda, que há uma "estagnação dessa pesquisa em comparação aos estudos de urbanismo, de assentamento rural e de achados romanos" (p.106).

Ao apontar as razões para essa situação, Hingley coloca que existe uma noção de que "já possuímos a maior parte do que precisamos saber e que resta pouca coisa para se alcançar. (...) O monumento parece ser fácil de se interpretar, seguro e imutável, uma fundação sólida sobre a qual baseamos nossas ideias sobre o passado antigo de nosso país" (p.107). Esse entendimento solidificado sobre o monumento parece contar com o grande auxílio das escolas de educação básica, onde "toda criança educada em escolas da Inglaterra dá a impressão de ter aprendido uma versão de 'fatos' básicos acerca do Muro, $e$, em geral, é difícil enfrentar esse saber, por causa de sua provável importância como parte de mitos de origem fundamentais sobre a Inglaterra, Escócia e a Grã-Bretanha" (p.108). É justamente um enfrentamento que tem pela frente os estudiosos que almejam tornar novamente o Muro de Adriano um objeto de pesquisa, pois há uma forte relação entre o Muro e as identidades nacionais, inglesa e escocesa, que já se encontram naturalizadas.

Por fim, Hingley questiona se há razões para o otimismo e, então, sugere "uma série de áreas que poderiam formar a base de uma nova agenda de pesquisa. Essa lista não se pretende, de modo algum, definitiva ou exclusiva, e um grande número de outras questões de pesquisa deveriam ser formuladas" (p.109). Algumas questões são levantadas e somente sugeridas: O muro 
articulou um discurso romano de identidade imperial? (p.109); Como as experiências acerca do Muro de Adriano estavam relacionadas à existência de outras fronteiras (p.110); Como o Muro valeu-se de paisagens pré-existentes e como sua presença influenciou as experiências de vários eleitorados (p.111); 0 que o Muro significou para as populações posteriores? (p.112). A pretensão do autor é chamar a atenção para as pesquisas que levem em conta a complexidade do monumento e, por outro lado, questionar a solidez e a imutabilidade que caracteriza os estudos concernentes ao tema atualmente.

Foram apresentadas algumas idéias gerais sobre essa importante obra que busca perceber o mundo da Roma clássica de forma mais problematizada, ao considerar as leituras que são feitas para legitimar ações no presente, bem como os mecanismos de apropriação do mundo antigo para usos contemporâneos.

Busca-se, ainda, estabelecer um diálogo entre História e Arqueologia clássica, em uma postura interdisciplinar, que permite rever os conceitos e categorias utilizadas em prol da construção de modelos teóricos menos rígidos e excludentes, abrindo possibilidades de produção de novos conhecimentos sobre o mundo antigo, e romano, em particular.

Enfim, é uma obra que concede ao público brasileiro o acesso à produção acadêmica internacional, mostrando que os estudos sobre a Antigüidade clássica, muitas vezes vistos como conservadores e elitistas, permitem abordagens múltiplas, onde a ênfase é dada ao caráter heterogêneo, plural e conflitivo do mundo antigo.

\section{Referências bibliográficas}

BERNAL, Martin. A imagem da Grécia Antiga como uma ferramenta para o colonialismo e para a hegemonia européia. Trad. Fábio Adriano Hering. In: Textos Didáticos Repensando o Mundo Antigo. IFCH/UNICAMP. n49, abril de 2005.

GARRAFFONI, Renata Senna; FUNARI, Pedro Paulo A. Morte e vida na arena romana: a contribuição da teoria social contemporânea. In: Fênix: Revista de História e Estudos Culturais. Janeiro/Fevereiro/ Março de 2007. Vol. 04, ano IV, nº1. p. 4. Disponível em: www.revistafenix.pro.br. 